\title{
Research on the Countermeasures of Sanya Smart Tourism Destination Construction against the Background of Global Tourism
}

\author{
Kun Zhang \\ Education Center of MTA \\ Hainan Tropical Ocean University \\ Sanya, China \\ e-mail: kunzhang@hainu.edu.cn
}

\author{
Jia Zhu* \\ Art College \\ Hainan Tropical Ocean University \\ Sanya, China \\ *e-mail: zhujia1217@163.com \\ *The corresponding author
}

\author{
Zhuang Li \\ College of Ocean Information Engineering \\ Hainan Tropical Ocean University \\ Sanya, China \\ e-mail: hitlz@163.com
}

\begin{abstract}
With the National Tourism Bureau to establish Hainan as the first whole country tourism creation Province, Sanya as the central tourist city of Hainan has the opportunity to develop, Sanya should combine tourism information technology to create a smart tourism platform. The level of tourism product development and tourism service management has been deepened, and Sanya is gradually built into the first class city, the destination of intelligent tourism. This article, taking the current research results of Intelligent Tourism as the background, further expounds and explains the theory of tourism achievements, pays attention to empirical analysis, provides data support for the construction of destination against the Background of intelligent tourism, and hopes to provide scientific basis for the accelerated development of tourism through the construction of Intelligent Tourism destination.
\end{abstract}

Keywords—Global Tourism; Smart Tourism; Smart City

\section{INTRODUCTION}

At the National Tourism Conference in 2016, the State Tourism Bureau decided that Hainan was the first provincial tourism demonstration province to explore and demonstrate the development of the whole country's tourism. As the leader of Hainan's global tourism development, Sanya has put forward a world class coastal tourist resort in 2017, and it is imperative to develop intelligent tourism and build intelligent tourism destination [1-2]. Intelligent tourism can meet the further requirement of tourist experience, which should be combined with modern information technology [3]. Starting with the opportunity of the whole region and the platform of intelligent tourism, the tourism resources of Sanya should be integrated in an all-round way, and the first class intelligent tourism destination in the country will be created [4].

\section{MAKING FULL USE OF THE IMPORTANT DEVELOPMENT OPPORTUNITIES OF ALL-FOR-ONE TOURISM}

All-for-one tourism is the trend of future tourism. Since Hainan established the international tourism island in 2009, the achievements have not been very obvious. At the time of the all-for-one tourism approaching, it is necessary to firmly grasp the development opportunities to set a solid foundation for building a smart tourism destination.

\section{A. Accurate positioning based on national and provincial all-for-one tourism}

The National Tourism Administration has identified Hainan as the first province to create a all-for-one tourism demonstration, which represents the country's great attention and strong support for Hainan tourism. Sanya City should take the country's tourism creation work in Hainan as a starting point and carry out the structural supply side reform of Sanya tourism, aiming to develop smart tourism destinations as the biggest proposal [5-6]. The city accurately position urban tourism, and coordinate the urban and rural construction of Sanya's central city, ten characteristic industrial towns, and 100 beautiful villages, and develop a "tourism +" format integration development model to build a new pattern of Sanya's all-forone tourism. Replacing the original concept of a tourist city with urban tourism. At the government level, the task of building a national all-for-one tourism should be divided into three "point, line and surface" layers, actively implement and carry out specific deployments, in the Sanya region, we should overcome the difficulties and develop all-around, meanwhile, we should coordinate urban and rural development, and vigorously promote the all-for-one tourism in City wide as well as smart tourism destination construction [7]. 
After the accurate positioning of Sanya Smart Tourism, it is necessary to integrate the development ideas of the all-for-one tourism and cooperate with the local economy and drive the development of industries related to model of the "tourism+" in the city, and focus on upgrading and transforming the industrial tourism. Further promoting the construction of tourism standardization services and refine the comprehensive tourism management service system. The integration of production and tourism, the slight and town, and the integration of city and tourism, and sharing between guests and holders, the all-forone tourism market environment strives to create a safe, transparent and comfortable experience .Realizing Sanya's allround area landscape, all-round area leisure activities, and allround area tourism, and build Sanya into a national tourism demonstration zone, a smart tourism destination around the South China Sea, and a world-class tropical coastal tourism boutique city [8].

\section{B. Achieving the integration of dotted and lines in cities and town, and differentiated development of various districts as well}

Sanya's all-for-one tourism development and smart tourism destination construction must be carried out simultaneously from urban and rural areas, coordinating urban and rural development, using "double construction" and "double city" to accelerate urban scenic area transformation, and using beautiful rural area construction to promote rural quality construction and comprehensive development of the point and line, which will be carried out to build a new pattern of tourism in Sanya. The focus should be on improving the new "six-six-three" region tourism industry system, namely, coordinating six major tourism industries, such as green agriculture and emerging culture, strengthening the six major tourism elements such as star-rated hotels and seafood, and developing three new tourism product such as low-height sightseeing, the traditional elements of tourism have been further enhanced in 2020, the end of the 13th Five-Year Plan, the tourism industry in Sanya has basically been laid, and the new industrial pattern of allfor-one tourism and smart tourism has been upgraded in all directions.

Sanya should focus on the four administrative regions of Yazhou, Tianya, Jiyang and Haitang, and promote the development of smart tourism and all-for-one tourism in Sanya. The western Yazhou District should accelerate the development of historical and cultural areas by combining the development of Pannan Mountain Cultural Tourism and the construction of Sanya Creative Industry Park [9]. The central Tianya District should speed up the construction of urban light rail lines and the construction of the new maritime airport in Sanya. The major transportation infrastructure can guarantee the optimization of the coastal tourism industry and the upgrading of the Sanya Bay and Hongtang Bay. The central Jiyang District will upgrade the existing industry of Yalong Bay, and create more international high-level convention and exhibition centers to build Yalong Bay into a base of tourism, leisure activities, and diplomatic affairs. The Haitang District in the east continues to focus on the construction of modern service industry parks [10]. With the absolute advantages of the national coast, it integrates existing high-end medical service, duty-free shopping, prestigious school education and high-end tourism projects such as Atlantis to continuously improve the quality of tourism products and the value of the city charm. The four districts of Sanya are linked together and integrated throughout the region, eventually forming a smart tourism destination with all-round development.

\section{CREATING A SMART TOURISM INFORMATION PLATFORM IN ALL-AROUND}

Sanya should expand its smart city application field as a starting point, continuously improve the construction of smart tourism information platform, and integrate industrialacademic-research into the Sanya smart tourism platform to provide basic services for smart tourism destinations.

\section{A. Expanding the application platform of smart city application and perfecting the platform construction}

Sanya's smart city construction includes two top-level designs, two security systems, three information infrastructures, and four major application areas. Among them, the two toplevel systems refer to the urban data exchange and sharing system and the big data application decision support system; the two guarantee systems refer to the information management with performance evaluation system and the information security guarantee system; the three information systems refer to during the smart city construction, the necessary elements "cloud", "net" and "number" - cloud computing center, urban basic network and urban basic database of economy, population, legal person, space geography, etc.; The four application areas are: one is the smart life field aiming at improving the quality of life of urban residents, two is the smart city management field aiming to improve the city's refined management level, and the third is the smart government affairs field aiming to improve the government's efficiency and service level the fourth is the field of smart tourism with the goal of improving tourism management and service levels.

\section{B. Integrating production, study and research into Sanya Smart Tourism Platform}

With the acceleration of the national tourism stage and the global Internet era, the tourism informationization construction tests the overall service level of Sanya to promote specialized tourism cities. Sanya City should seek to cooperate with international and domestic key industry-university research institutions within the Internet + industry to build a cloud travel information platform, and realize behind-the-scenes big data management, and make full use of big data to travel and upgrade existing Sanya City management mobile applications and tourism life mobile applications, meanwhile, we should further build and improve the Sanya tourism data open network platform, established data service systems and tourism market monitoring, and accelerate the comprehensive development of the tourism big data industry.

At present, the facilities which are completed in Sanya,such as citizen visitor center , 12301 travel complaints line, 12345 government hotline and tourism data large sand table have achieved remarkable results. It has been linked with the 
functional departments of industry and commerce, law enforcement, public security, traffic management, etc., city service data and the information on the six major tourism elements such as accommodation, travel, purchase and entertainment has been displayed in real time, providing scientific and powerful data resources for the construction and management of Sanya smart tourism destinations. Sanya should continue to use the cloud computing center as a platform to build a smart tourism destination as its goal, develop a tourism big data industry, and realize the collection, exchange and sharing of information data between tourism authorities and the tourism industry, and form a connected mechanism that big data are equally open to the government and enterprises, promoting the intelligent operation management of the tourism industry and tourism industry in Sanya [11].

\section{BuILDING SANYA INTO A SMART TOURIST DESTINATION}

The construction of smart destinations in Sanya is by no means a day's work. It is necessary to do top-level design and coordinated development, and establish a leading group as soon as possible, and seize the key points of smart tourism, and carry forward local culture to deepen the construction of smart tourism destinations.

\section{A. Establishing the Smart Tourism Leading Group}

Leading by the Sanya Tourism Development Committee, and contact the tourism functional departments, tourism experts, tourism enterprise leaders, tourism associations, etc. to establish the Sanya Smart Tourism Leading Group to determine the short-term, medium-term and long-term development strategies of the destination wisdom of Sanya from the government, enterprises, scientific research, market and other aspects. it will gradually implement the construction of smart tourism destinations in steps and stages. From the perspective of strategic overall, the development direction of high-standard positioning smart tourism in Sanya will lead the planning and construction of smart tourism destinations [12].

\section{B. Seizing the four key points of smart tourism}

The strategy of smart tourism destinations should grasp the four key points of smart tourism: intelligence and automation, tourists-centralization, integrated tourism resources, collaborative innovation and development. Among them, intelligence and automation are the software support for smart tourism. After visiting Sanya, visitors can automatically learn about local tourism information and travel services through mobile devices and online media, and provide feasible suggestions for the next travel plan. Taking tourists as the center, we must use the Internet, big data, Internet of Things and other information technologies and emerging platforms to let the tourists in Sanya learn about the service information provided by Sanya Tourism through a diversified information export mode, and get convenient Internet + services. Integrating tourism resources is to use mobile information service equipment to introduce information to the on-site tourists and potential tourists within the scope of tourism products such as major scenic spots, hotels, shopping malls and parks in Sanya; scenic spots, star-rated hotels and tourist services Institutions and other enterprises use the data of the resource integration platform to learn about the dynamics of tourists and improve the service level. The Sanya Tourism Commission can also provide data and material support for the municipal government's tourism-related decision-making according to the statistics of the big data of the citizen visitor center.

\section{Developing smart tourism must be rooted in local culture}

Sanya's own cultural format is closely linked with the international frontier tourism market and the existing tourism model, transforming the local cultural characteristics of Tianya into international tourism products for sales. The construction of smart tourist destinations is to provide tourists with convenient information services as much as possible, and to provide a local culture and sense of belongings for the grassrooted tourists who pursuit personalities and differences and to realize the resonance feeling of smart tourism. Visitors will unconsciously recognize the connotation of Sanya's native culture and develop and upgrade with the city. In this way, the construction of smart tourism destinations has a foundation and a steady stream of forward momentum.

\section{SUMMARY}

Sanya City is currently constructing a smart tourism city, but now it only stays at the stage that each scenic spot developing on their own, lacking strategic, planned and systematic tourism planning; scenic spots and related tourism enterprises lack smart management and smart service measures; and are lack of talent. Sanya City should seize the development opportunities of smart tourism cities, rely on tourism professional institutions and scientific research systems of higher education institutions, and establish a perfect rural tourism development system with tourists as the center to promote the rapid and efficient development of smart tourism in Sanya.

The global tourism brings unprecedented opportunities and challenges to the construction of Sanya's smart tourism destinations. Sanya tourism authorities and tourism enterprises should fully understand the frontier, necessity and importance of smart tourism destination construction, and jointly create and improve wisdom tourism information platform, making a due contribution to the construction of Sanya's smart tourism destination together.

\section{ACKNOWLEDGMENT}

This research was financially supported by the Sanya Planning Projects of Philosophy and Social Sciences (No.SYSK2018-06, No.SYSK2017-03).

\section{REFERENCES}

[1] J.H. Song, X.B. Huang, K. Zhang, "Smart tourism based on the integration of Sanya Tourism WeChat public platform and public services,” Intelligent City, vol. 04, No. 05, 2018, pp.1-2.

[2] L.N. Shao, X.B. Huang, K. Zhang, "Building a Smart Touris m City and Leading the Pioneer of Smart Tourism-Taking the Sanya Visitor 
Center as an Example,” Intelligent Building \& Smart City, No. 04, 2018, pp.71-73.

[3] K. Zhang, Z. Li, "Analysis and Research on Information Education in Colleges and Universities in Hainan Minority Areas," Continue Education Research, , No. 07, 2013, pp.127-128.

[4] K. Zhang, X.B. Huang, W. Zhou, "Researchon the Teaching Reform of the Tourism Information System Course of the Master of Tourism Administration(MTA) - Take Hainan Tropical Ocean University as an Example," China Sciencepaper, [2017-08-25]. http://www.paper.edu.cn/releasepaper/content/201708-104.

[5] W. Zhou, X.B. Huang, J. Zhu, K. Zhang, "The Research and Development of Sanya Big Tourism Performing Arts Culture Brand Based on The Romantic Show of Sanya. Advances in Computer Science Research,” Advances in Computer Science Research, vol. 73, 2017, pp.678-781.

[6] J. Zhang, "Problems and Countermeasures in the Construction of Smart Tourism in Sanya,” Tourism Overview, No. 05, 2016, pp.71+73.
[7] J.Y. Li, H.J. Gao, "Global Tourism From the Perspective of Informatization,” Tourism Tribune, vol. 31, No. 09, 2016, pp.24-26.

[8] K. Zhang, "The Application of Computer Personnel Training Practice Teaching Research in Colleges and Universities---Take Qiongzhou University as an Example,” Journal of Qiongzhou University, vol. 19, No. 02, 2012, pp.94-96.

[9] F.Y. Wei, "College Tourism Talent Cultivation in the Background of Smart Tourism," Journal of Changchun Normal University(Natural Science), vol. 36, No. 02, 2017, pp.83-86.

[10] K. Zhang, "Promote Construction by Evaluation and Improve Construction Quality Undergraduate Computer--Take Introduction to Computer as an Examp le,” Journal of Qiongzhou University, vol. 20, No. 05, 2013, pp.125-128.

[11] Y.H. Jiang, "The basic concept and theoretical system of s mart touris m," Tourism Overview, No. 02, 2016, pp.27.

[12] W.D. Jin, "Smart Tourism and Tourism Public Service System Construction,” Tourism Tribune, No. 02, 2012, pp.5-6. 